\title{
Asthma and allergy crisis in Puerto Rico: a must do proposal
}

\author{
Syed A. A. Rizvi ${ }^{1}$, Marcos A. Sanchez-Gonzalez ${ }^{2}$, Jesús Irizarry Mora ${ }^{3}$, Sultan S. Ahmed ${ }^{4}$, Ronda Lunn ${ }^{5}$, \\ Troy Grogan ${ }^{6}$
}

\begin{abstract}
${ }^{1}$ Department of Pharmaceutical Sciences, Hampton University School of Pharmacy (HUSOP), Hampton, VA, USA; ${ }^{2}$ Lake Erie College of Osteopathic Medicine, Bradenton, FL, USA; ${ }^{3}$ Puerto Rico's Governor's Office, San Juan, PR, USA; ${ }^{4}$ Department of Biochemistry and Molecular Biology, Miller School of Medicine, University of Miami, Coral Gables, FL, USA; ${ }^{5}$ JAS Medical Management, Miramar, FL, USA; ${ }^{6}$ MedScience Research Group, Inc., Delray Beach, FL, USA

Correspondence to: Dr. Syed A. A. Rizvi. Department of Pharmaceutical Sciences, Hampton University School of Pharmacy (HUSOP), Hampton, VA 23668, USA. Email: syed.rizvi@hamptonu.edu.
\end{abstract}

Submitted Jul 21, 2019. Accepted for publication Dec 03, 2019.

doi: $10.21037 /$ jtd.2019.12.15

View this article at: http://dx.doi.org/10.21037/jtd.2019.12.15

Allergy is the immune system response when a person comes in contact with an environmental allergen (pollen, certain plants, animals, etc.), which may be benign to many others. The Commonwealth of Puerto Rico (PR) is a Territory of the United States of America (US) where chronic disease such as asthma and allergy is much higher than other US states (1). In fact, this is not exclusively found in the adult population, as children living in PR have been disproportionately affected with asthma compared with children living in the US (2). To add fuel to the fire, Puerto Ricans have less access to healthcare providers due to a medical workforce labor shortage which has been hampering the Island Territory for decades (3). Since Hurricane Maria devasted the Island in 2017, more doctors have fled PR to work in the Continental US (4). For instance, one major gap left behind is the specialist/patient ratio for allergy sufferers. The Puerto Rican Physician Workforce Data Book reports only 12 allergy specialists 5 of whom are Board Certified with American Academy of Allergy, Asthma and Immunology in the Commonwealth of PR to manage the approximate 3.4 million population (5), which is a dramatic $1: 310,000$ specialist to population ratio. Anecdotal feedback from physicians currently practicing in PR report the actual direct patient to specialist ratio may be terribly worse given the population shift from commercial payors to State based payors as result of large employers relocating after the recent Hurricane. Without employment, families and children do not have access to commercial insurance plans that employers provide and therefore rely on the Medicaid 'capitated' Island Government sponsored health plan. Currently, this health plan does not thoroughly cover all specialty services. So, it's assumed by practicing physicians that there are less than the reported 12 practicing allergist's whom are actually treating the allergy and asthma patients in PR. This obvious health disparity only places more pressure and further burden on primary care and general pediatricians to care for their population.

It is a well reported fact that the allergy and asthma exacerbating factors vary as per the geographical, climate, and socioeconomical situation. Many researchers are studying the underlying causes, including genetics, vitamin D deficiency, increased allergen levels in homes especially after the recent hurricane, poor dietary choices, air pollution and chronic stress, etc. Atopy considerably mediated the asthma association in this population: allergic rhinitis accounted for $22 \%$ to $53 \%$ of the association with asthma, and sensitization to cockroach mediated $13 \%$ to $20 \%$ of the association with abnormal forced vital capacity and $29 \%$ to $42 \%$ of the association with emergency department visits for asthma (6). Skin, being the largest organ in terms of surface area and the first protection against pathogens, also provides visible indication of various inflammatory processes, including allergy. Allergy skin testing is a quick and easily administrable procedure that can be used in almost any outpatient setting. Results may be further confirmed by more specific blood testing and in most cases, desensitization treatment is the remedy.

While not giving up on Rose's epidemiological dictum (7) that "small changes in large populations are likely to be more effective than large changes in small numbers", it is evident 
that new methods for managing allergy in PR is called for. It is understood that it will take many years to recruit or train allergy specialists and immunologists to address the allergy suffering population. Studies with similar allergy population constraints have shown that up to 50 percent of allergy specialist referrals could be dealt with by primary care providers (PCPs) with interest and additional training in allergy management, allowing specialty services to focus on more complex cases thus reducing patients' wait for first-time appointments (8). With more specific training, PCPs would be positioned to provide diagnosis and management of mild to moderate allergic conditions, while referring complex and severe allergy and asthma sufferers to specialists. This referral process will enable specialists to focus on the more complex allergy and asthma problems while addressing this important health care disparity

Puerto Rican local government, hospital administrators, universities, public health workers, primary care and pediatricians are collectively organizing a new professional society to be established in the City of Mayaguez, namely the Puerto Rican Allergy and Immunotherapy Society (PRAIS) with a charter to improve knowledge and practical skills of primary care and non-allergist medical professionals in allergy diagnosis and allergen immunotherapy. The new society will also aim to foster research in the areas of community, primary and population health, clinical and translational, as a model that could be replicated in other countries that are unfortunate to have asthma and allergy sufferers without the ideal medically trained specialist community. The aims and commitments of this society also dovetail with broader economic and social agenda items to reduce healthcare costs and improve quality of lives throughout PR.

The Society will 'strongly' advocate for appropriate physician reimbursement, cost reduction, and improved financial support for allergic disease and asthma management of Puerto Ricans, with a strict policy that it not be a self-serving member objective. This could be achieved through evidence-based business case analysis, collective input and pilot studies throughout the Puerto Rican population.

One such example of potential economic advantages are the reported health care savings of Florida Medicaid patients who were newly diagnosed with allergic rhinitis and treated with allergen immunotherapy that showed they incurred 38\% lower healthcare costs after 18 months of follow-up compared to non-treated control patients. Savings from this study were observed as early as the three- month stage of treatment. Allergic children treated with allergen immunotherapy incurred $42 \%$ less health care costs compared to untreated kids: $\$ 5,253$ versus $\$ 9,118$ resulting in $\$ 3,865$ savings per child for the studied period to the Florida State Government (9).

PRAIS proposes to have its first annual meeting in January 2020 and will invite scientists, medical practitioners, residents and students from the Continental US and around the world to visit the Island Territory and participate in scientific and medical exchange, collaboration and continuing medical education.

\section{Acknowledgments}

None.

\section{Footnote}

Conflicts of Interest: The authors have no conflicts of interest to declare.

Ethical Statement: The authors are accountable for all aspects of the work in ensuring that questions related to the accuracy or integrity of any part of the work are appropriately investigated and resolved.

Open Access Statement: This is an Open Access article distributed in accordance with the Creative Commons Attribution-NonCommercial-NoDerivs 4.0 International License (CC BY-NC-ND 4.0), which permits the noncommercial replication and distribution of the article with the strict proviso that no changes or edits are made and the original work is properly cited (including links to both the formal publication through the relevant DOI and the license). See: https://creativecommons.org/licenses/by-nc-nd/4.0/.

\section{References}

1. Hunninghake GM, Weiss ST, Celedón JC. Asthma in Hispanics. Am J Respir Crit Care Med 2006;173:143-63.

2. Langellier BA, Martin MA, Canino G, et al. The health status of youth in Puerto Rico. Clin Pediatr (Phila) 2012;51:569-73.

3. Roman J. The Puerto Rico Healthcare Crisis. Ann Am Thorac Soc 2015;12:1760-3.

4. Echenique M, Melgar L. (2018, May 11). Mapping Puerto Rico's Hurricane Migration With Mobile Phone Data. Retrieved March 17, 2019. Available online: https://www. 
citylab.com/environment/2018/05/watch-puerto-ricoshurricane-migration-via-mobile-phone-data/559889/

5. 2017 State Physician Workforce Data Book. (n.d.). Available online: https://www.aamc.org/download/484586/ data/puertoricoprofile.pdf

6. Forno E, Acosta-Pérez E, Brehm JM, et al. Obesity and adiposity indicators, asthma, and atopy in Puerto Rican children. J Allergy Clin Immunol 2014;133:1308-14.

7. Egger GJ, Binns AF, Rossner SR. The emergence of "lifestyle medicine" as a structured approach

Cite this article as: Rizvi SAA Sanchez-Gonzalez MA, Mora JI, Ahmed SS, Lunn R, Grogan T. Asthma and allergy crisis in Puerto Rico: a must do proposal. J Thorac Dis 2020;12(3):11421144. doi: $10.21037 /$ jtd.2019.12.15 for management of chronic disease. Med J Aust 2009;190:143-5.

8. Diwakar L, Cummins C, Lilford R, et al. Systematic review of pathways for the delivery of allergy services. BMJ Open 2017;7:e012647.

9. Hankin CS, Cox L, Lang D, et al. Allergen immunotherapy and health care cost benefits for children with allergic rhinitis: a large-scale, retrospective, matched cohort study. Ann Allergy Asthma Immunol 2010;104:79-85. 